\title{
As cidades e as narrativas plásticas modernistas
}

Academicismo e modernismo em Santa Catarina ${ }^{1}$

\author{
Sandra Makowiecky ${ }^{2}$ \\ Participantes do Grupo de Pesquisa (SC): Marina Rieck Borck ${ }^{3}$ Giorgio Vicenzo \\ Filomeno $^{4}$ \\ Participantes do Grupo de Pesquisa ( AL): Ana Lúcia Gil, Kamilla Nunes, Letícia \\ Weiduschadt, Rachel Reis de Araújo ${ }^{5}$
}

\begin{abstract}
Resumo: Este artigo é decorrente de uma pesquisa que deverá mapear e agrupar os principais artistas identificados com o academicismo e modernismo em Santa Catarina, entretanto, especificamente nesta abordagem comparece uma problemática sobre o arsenal imagético, particularmente no que se refere às questões relacionadas à cronologia e anacronismo, texto e contexto, cópia e original, proximidade e distância, superfície e profundidade, problemática central da pesquisa, utilizando imagens das cidades e modernismo como fio condutor.
\end{abstract}

Palavras - chave: Academicismo; Modernismo; Santa Catarina.

O contexto - A pesquisa proposta problematiza uma história da pintura em Santa Catarina entre meados dos séculos XIX e XX, especialmente considerando como base levantamentos feitos com imagens encontradas em sites e catálogos relacionados a este assunto e que tematizam através de cenas, paisagens, objetos e retratos questões próprias à linguagem pictórica. Serão privilegiados os diferentes aspectos e

1. -O presente texto é parte integrante de uma pesquisa intitulada Academicismo e modernismo em Santa Catarina- UDESC, Centro de Artes, cujo levantamento já conta com mais de 500 imagens e conta com a participação de bolsistas de iniciação científica.

2 Orientadora, professora do Departamento de Artes Plásticas do Centro de Artes - UDESC.

3 Acadêmica do Curso de Bacharelado em Artes Plásticas - Ceart/UDESC, bolsista PROBIC, UDESC, participante da pesquisa Academicismo e Modernismo em Santa Catarina.

4 Acadêmico do Curso de Bacharelado em Artes Plásticas - Ceart/UDESC, bolsista PROBIC, UDESC, participante da pesquisa Academicismo e Modernismo em Santa Catarina.

5 Acadêmicas participantes do projeto Academicismo e Modernismo na América Latina, do mesmo grupo de pesquisa das orientadoras Sandra Makowiecky (coordenadora do projeto SC) e Rosangela Miranda Cherem ( coordenadora do projeto AL). Ana Lúcia Gil, bolsista PROBIC, acadêmica do curso de Artes Plásticas; Kamilla Nunes, bolsista PROBIC, acadêmica do curso de Artes Plásticas; Letícia Weiduschadt, bolsista PROBIC, acadêmica do curso de Artes Plásticas; e Rachel Reis de Araújo, bolsista voluntária e acadêmica do curso de Artes Plásticas. 
interlocuções que se apresentam para tramar e delimitar uma análise das sensibilidades e percepções artísticas, tais como, principalmente, proximidade e distância.

Neste sentido, temos que entender Santa Catarina na periferia de centros como Rio de Janeiro e São Paulo e mais recentemente, além destes, com Porto Alegre e Belo Horizonte. Entretanto esses centros estão na periferia de centros artísticos do mundo, cada qual em seu momento histórico. No século XIX, por exemplo, o Rio de Janeiro era centro para Florianópolis, mas periferia para Paris. Os centros irradiadores culturais vez por outra mudam. De todo modo, continuamos periferia de alguma coisa. Muitas vezes um tipo de representação proposto encontra terreno fértil para se enraizar, como foi o caso do neoclassicismo no Brasil, no século XIX, uma vez que seu universo simbólico supria os anseios políticos, sociais e culturais da classe dominante. Portanto, não há como relegar o fato de que são as nossas próprias condições históricas, sociais e econômicas, que também determinam nossa produção artística.

Segundo evidências do próprio campo artístico, a relação entre centro e periferia não deve ser valorativa, não deve ser vista como uma relação entre avanço e atraso. Ao contrário, é um jogo móvel, sujeito a acelerações e tensões repentinas, ligadas a modificações não apenas do campo artístico como também do social e político. A presença de referências de outras manifestações artísticas evidencia a existência de uma circularidade de idéias percebidas na diacronia e sincronia dos acontecimentos. Se fossemos nos levar pela suposta linha reta da história, tal perspectiva só levaria a concluir que a produção em arte em Santa Catarina, que é o objeto desta pesquisa, está algumas décadas atrasada na história. Mas este raciocínio de nada serve para o estudo da nossa produção plástica. Como diz Annatereza Fabris: "A arte moderna produzida no Brasil, pelo menos no caso das artes plásticas, é moderna numa acepção peculiar e local, mas não se pensada no âmbito das propostas européias” (1994, p.20).

As cidades - As relações entre cidade e objeto artístico aparecem em autores como Francastel e Argan, que introduzem aspectos subjetivos na análise das formas urbanas simbologia, imaginário - considerando-as como produto cultural. Dentro do processo histórico das cidades, não cabe uma compreensão de temporalidade cronológica, isso porque elas abrigam uma trama de tempos descompassados que se cruzam de formas diferentes, gerando mudanças constantes.

A cidade [...] nunca é absolutamente sincrônica: o tecido urbano, o comportamento dos citadinos, as políticas de planificação urbanística, 
econômica ou social desenvolvem-se segundo cronologias diferentes. Mas ao mesmo tempo, a cidade está inteira no presente (LEPETIT, 2001, p. 139).

Tanto a subjetividade do imaginário quanto a dimensão histórica da relação entre forma urbana e sociedade estão presentes no conceito de paisagem. Ao mesmo tempo, a paisagem é fruto da história pois em cada época o processo social imprime materialidade ao tempo, produzindo formas/paisagens ( LUCHIARI, 2001, p.12). A paisagem constitui-se assim na representação de diversos momentos históricos de um grupo social, como observa Milton Santos: Considerando um ponto determinado no tempo, uma paisagem representa diferentes momentos de desenvolvimento de uma sociedade. A paisagem é o resultado de uma acumulação de tempos (SANTOS, 1992, p.13).

A noção de cotidiano é desenvolvida por Michel de Certeau, para quem o espaço é um lugar praticado. É um lugar percebido, ou seja, para a mesma forma urbana podem corresponder experiências espaciais distintas (CERTEAU, 2003, p. 176-203) bem como representações plásticas distintas. Na relação entre forma urbana, estrutura social e tempo, deve-se levar em conta Lepetit quando este afirma que "as sociedades urbanas procedem continuamente a uma reatualização e a uma mudança de sentido das formas antigas, reinterpretando-as constantemente” ( LEPETIT, 2001, p.147).

\footnotetext{
No termo cidade [...] acumula-se uma grande soma de experiências históricas.[...] As cidades desenvolveram-se de uma maneira que chamamos espontânea, mas que, na realidade, era determinada pela evidência que a figura histórica da cidade tinha na consciência individual e coletiva.(ARGAN, 1998, p.240).
}

No conceito de paisagem urbana, enfatiza-se a sua dimensão simbólica enquanto rede de significados e significantes; na sua dimensão histórica, é expressão dos laços que ligam o presente à herança do passado. Se estudarmos a forma sem conteúdo, iremos reduz a realidade a um simulacro, eliminando a subjetividade do cotidiano, nos diz Certeau (2003). E então, o que podem nos dizer os artistas? Como as cidades, as esquinas e praças aparecem na representação plástica modernista?

É nos anos de 1920, com a industrialização em curso, que se verificam processos de urbanização mais nitidamente modernos, e os modernismos que tem lugar nesse período se beneficiam da reconfiguração das principais cidades brasileiras, mas mesmo assim são tímidos. Nos diz Peixoto( 2006), que basta lembrar que dois ensaístas do modernismo paulista, Paulo Prado e Sérgio Milliet, diretamente envolvidos com a 
renovação operada nas artes, como analistas da sociedade nacional, voltam-se ou para o passado e para as raízes do Brasil ou para o universo rural.

Se para Beatriz Sarlo, o "desejo de cidade é mais forte na tradição argentina, que as utopias rurais"( 1990), na tradição brasileira, mesmo nos anos 1920 que também aqui “ apresentam a mudança de modo espetacular”( p.32) - é preciso, senão inverter, ao menos suavizar a assertiva: os universos rural e tradicional competem de modo decidido com o desejo de cidade de nossos modernistas. (PEIXOTO, 2006, P. 178-9).

Diz ainda a autora, que a dualidade sertão/litoral é também parte constitutiva da imaginação social sobre o Brasil e se desdobra, em momentos variados, em outros dualismos espaciais recorrentes nas interpretações sobre o país a partir do século XIX, como campo/cidade, norte/sul e que os temas das oposições podem variar, mas remetem sempre a um mesmo núcleo: todas tematizam as dramáticas relações entre tradição e modernidade entre nós. Os discursos sobre as cidades implicam lidar com a ordem do simbólico e também com a ordem física, com a realidade das ruas, praças e traçados, embora as duas dimensões- a da "cidade letrada" e da "cidade real", como quer Angel Rama (1985), jamais se confundam.

A literatura e a arte do modernismo experimental que surgiu nos últimos anos do século XIX, se afirmou nos primeiros 40 anos do século XX e continua até hoje, podese dizer, foi uma arte das cidades, principalmente das cidades poliglotas, cosmopolitas. Quando pensamos em modernismo, não podemos deixar de evocar cidades com cafés, revistas e galerias de arte, locais onde se destilam as novas estéticas. Sempre existiu uma ligação entre as artes, especialmente a literatura e as cidades. E se o modernismo é uma arte especificamente urbana, em parte é porque o artista moderno foi capturado pelo espírito da cidade moderna, que em si é o espírito de uma sociedade tecnológica moderna. A tendência modernista está profundamente enraizada nas capitais culturais da Europa e se espalha pelo mundo. Portanto, não é casual que o século XX seja o grande século de urbanização ocidental. Sobre as cidades como centros ciclônicos de civilização, diz Bradbury;

Ecos formais desse processo ressoam claramente na forma e na falta de
forma, na criação e na descriação da arte modernista. O caos cultural
alimentado pela cidade populosa em crescimento constante, Torrre de Babel
contingente e poliglota, é reproduzido como análogo caos, contingência e
pluralidade nos textos literários modernos, no desenho e na forma da pintura
modernista (1989, p.78)

Além de arte metropolitana, o modernismo é uma arte cosmopolita: uma cidade leva a outra no típico percurso estético até a metamorfose da forma. Irradiavam 
influência e mantinham contato, e em larga medida é devido a essa fecundidade nas comunicações e contatos que o modernismo constitui um movimento internacional. $\mathrm{O}$ modernismo no Brasil e no resto do mundo, teve nas cidades, seu habitat natural. É da vida e da experiência urbanas que os artistas e intelectuais ligados aos diversos modernismos surgidos no começo do século $\mathrm{XX}$ retiram a matéria prima de sua produção ( Bradbury, 1989).

Os artistas e as imagens da cidade - No contexto da modernização, busca-se evidenciar a relevância daquilo que é local e peculiar na vida da cidade. O cotidiano da cidade surge do convívio do novo com o antigo. Voltar-se para a vida, o dia-a dia, falar de temas corriqueiros, que, por estarem incorporados ao cotidiano, já não são percebidos como elemento diferenciador da vida na cidade e do povo, são questões recorrentes nos trabalhos dos artistas, que empenharam as suas sensibilidades na valorização desses aspectos simples, populares, óbvios até. E procuraram transformar a vida em arte para poder representar com a arte a vida das pessoas comuns. Temas que antes eram experimentados na privacidade vieram a público, tornando-se capazes de figurar num espaço destinado à arte.

A ambição do modernismo em querer exprimir o imaginário brasileiro, faz
com que procure reconstituir esse imaginário a partir de suas origens. Deste
modo, a imagem do modernismo não se limitará ao perímetro das cidades,
retomando como signos algumas características formais próprias à paisagem
interiorana, tais como as construções populares, ou ainda as casas-grandes e
as igrejas coloniais esquecidas no tempo (ZILIO, 1982, p.78).

Aparecem temas como: casas simples, quintais, esquinas, praças, festas populares, os lugares da cidade, com as ruas, praças, morros, cais, as personagens presentes no cotidiano. Muitos artistas tentavam dar conta da paisagem física e humana das cidades, construindo uma iconografia local, nos diz Chiarelli ( 1994), lembrando que os padrões do modernismo brasileiro já estão presentes no final do século XIX e ganham importância com a transformação da Academia Imperial de belas Artes em escola Nacional de Belas Artes. Surge daí um paisagismo nacionalista que vai servir de parâmetro para a construção de uma arte nacional no início do século XX. Os artistas assumem as condições locais caracterizando-as e tornando-as positivas. O modernismo instaurou-se sob o signo do nacionalismo, projetando para o futuro o que tentava resgatar do passado, estabelecendo alguns possíveis contornos para uma imagem brasileira. 
Há muito chegamos à conclusão de que a arte não é produzida num espaço vazio, de que nenhum artista é independente de predecessores e modelos, de que ele, tanto quanto o cientista ou o filósofo, é parte de uma tradição específica e trabalha numa área estruturada de problemas. O grau de maestria neste contexto e, pelo menos em certos períodos, a liberdade para modificar esses rigores são, presumivelmente, parte da complexa escala pela qual o êxito final é medido (GOMBRICH, 1986, p 24).

Ao falarmos de modernismo, podemos entender as características da nova mentalidade como as sintetizadas por Mário Barata (1983) baseadas no anticonvencional, no antideclamatório, na liberdade de se inventar poéticas, linguagens, sintaxes, de lidar com os sentidos, de colocar a composição subordinada a construção mental, de tornar o colorido não um fato de representação, mas de uma opção estética, desprezo aos padrões convencionais, necessidade de renovação, mas sobretudo, a liberdade absoluta de espírito, considerada como elemento criador por excelência.

Alejandro Xul Solar (1887-1963), argentino, é um dos mais representativos pintores da vanguarda latino americana. Em 1912 foi para a Europa onde ficou ate 1924. Beatriz Sarlo ( 2005) diz que sempre considerou os quadros de Xou Solar um quebra - cabeça de Buenos Aires, ficando impressionada com a paixão hierárquica e geometrizante, a exterioridade de seu simbolismo. Em suas proposições, Xul Solar antecipa-se ao Surrealismo, assim como tangencia o Maneirismo e o Dada.( Figuras. 1, $2,3)$.

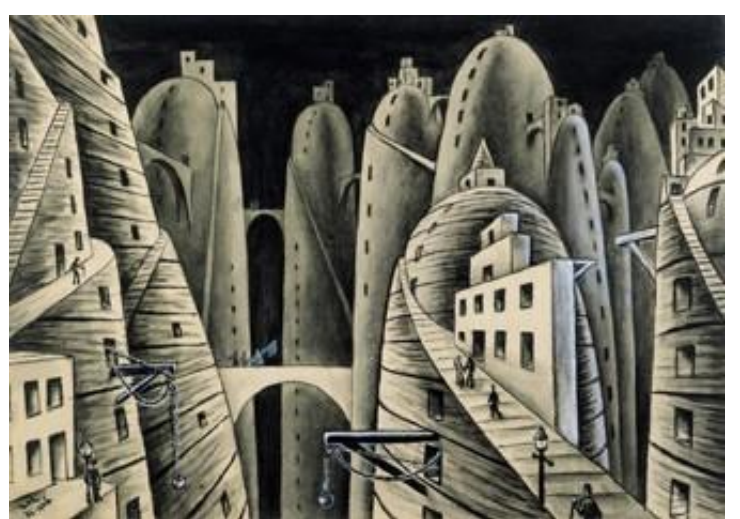

Figura 1

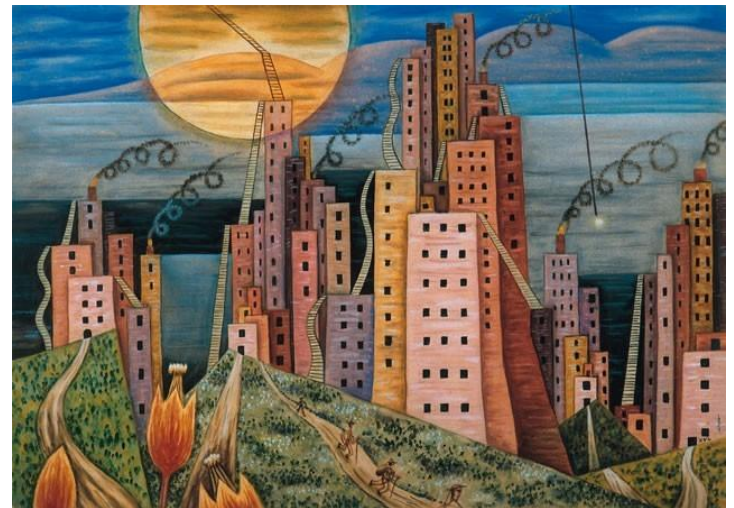

Figura 2

O que Xou mescla em seus quadros também se mescla na cultura dos intelectuais: modernidade européia e diferença rioplatense, aceleração e angústia, tradicionalismo e espírito renovador, crioulismo e vanguarda. Buenos Aires: o grande cenário latino americano de uma cultura da mescla. ( SARLO, 2005, p. 201).

Antonio Berni Rosário (Argentina -1905-1981), em 1925 ganha bolsa de viagem à Europa. Nesse momento, interessa-se por idéias socialistas, associa-se com os 
surrealistas e começa a pintar nesse estilo. Em 1930, regressa à Argentina. Trabalha com a temática social que permite compreender o cotidiano das cidades latinas, seus costumes e mitos regionais. Berni cria um universo onde dois mundos aparentemente antagônicos, se confrontam: o da arte culta e da cultura popular ( figura. 4 a figura. 7).

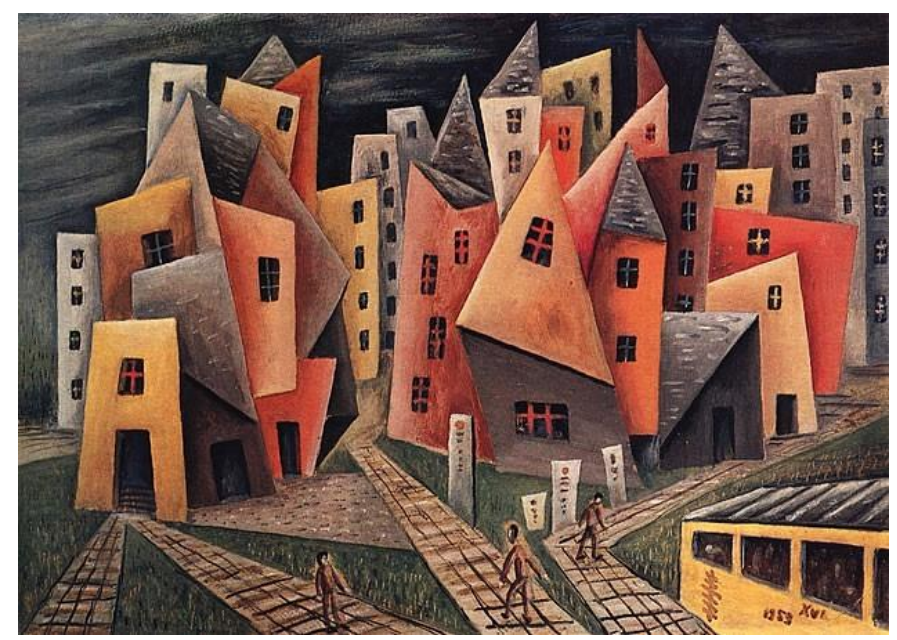

Figura 3

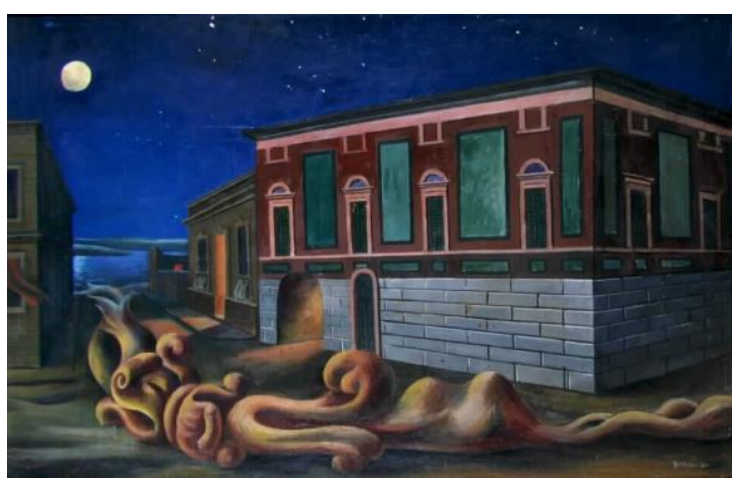

Figura 4

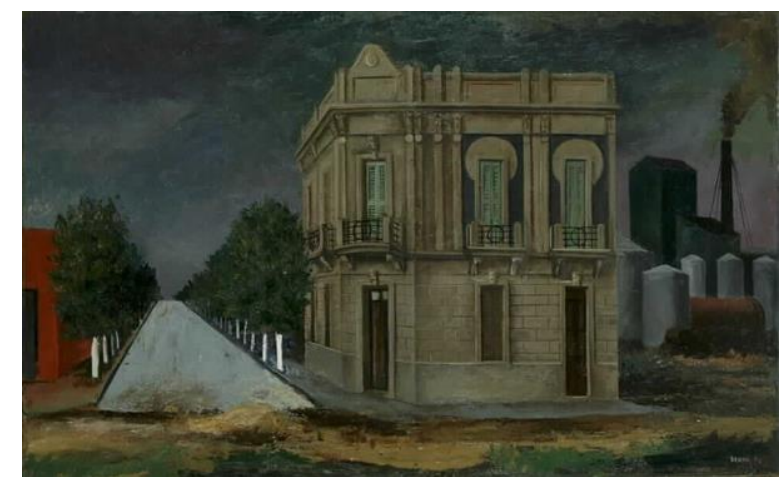

Figura 6

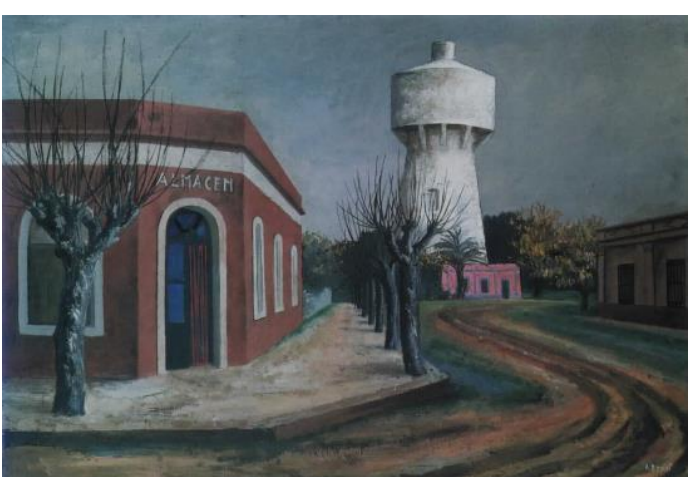

Figura 5

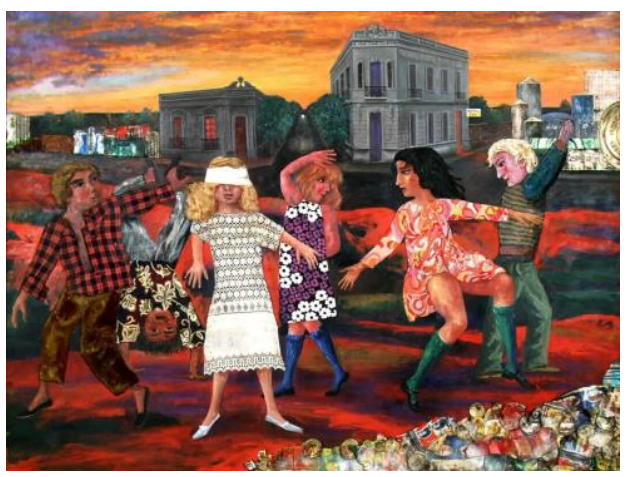

Figura 7

Jose Antonio Velasquez (Honduras -1906-1983). Fez uma arte ingênua e primitivista. Foi minucioso em suas obras. Nos quadros de Velazquez, onde vemos as telhas pintadas uma a uma, os cachorros urinando sobre as paredes ou os troncos e as 
pessoas ocupadas em algo. O cotidiano das cidades expresso em sua singeleza. ( figura 8 e 9$)$.

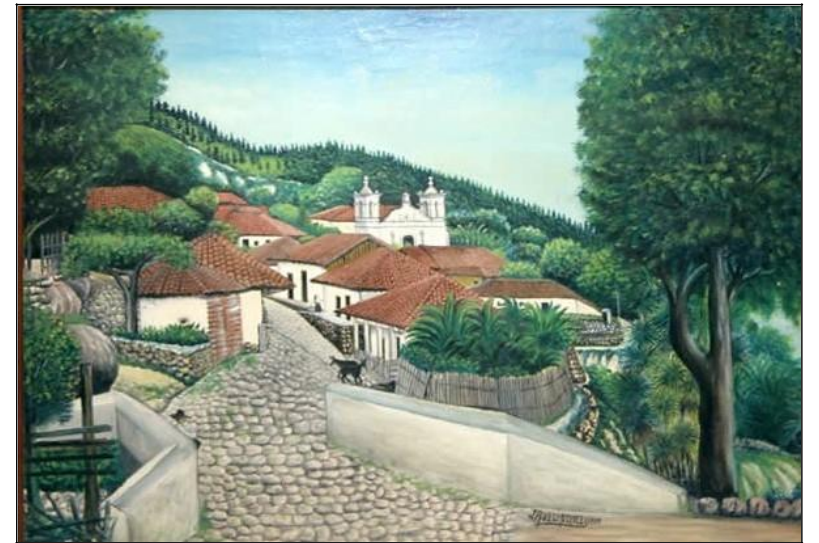

Figura 8

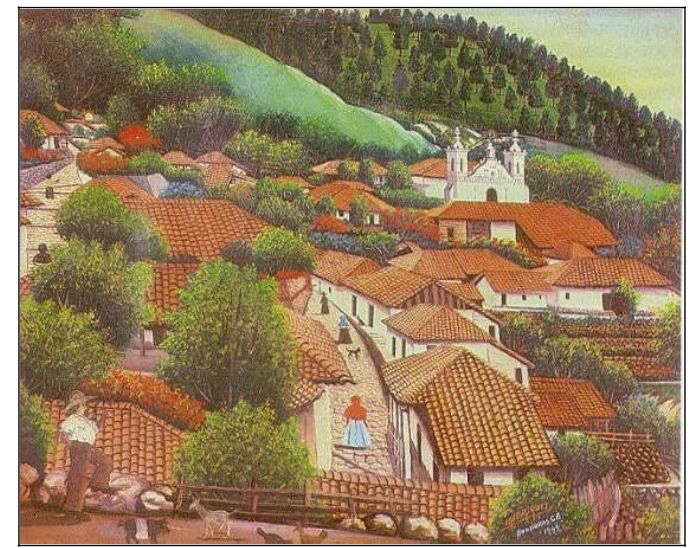

Figura 9

O venezuelano Rafael Monasterio (1884 -1961). Viaja à Espanha. Depois da criação da Escola das Belas Artes, surgiu um movimento acadêmico de pintura, impulsionado por pintores venezuelanos formados na Europa, a partir do qual a pintura venezuelana foi virando-se, cada vez mais, para a abstração geométrica e a arte cinética. Todavia, em Monasterio percebemos características modernistas de se voltar a um regionalismo (figuras 10 e 11).

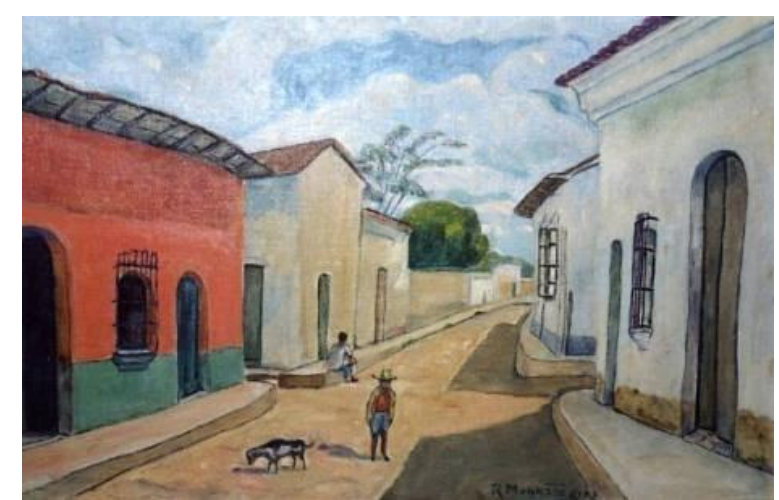

Figura 10

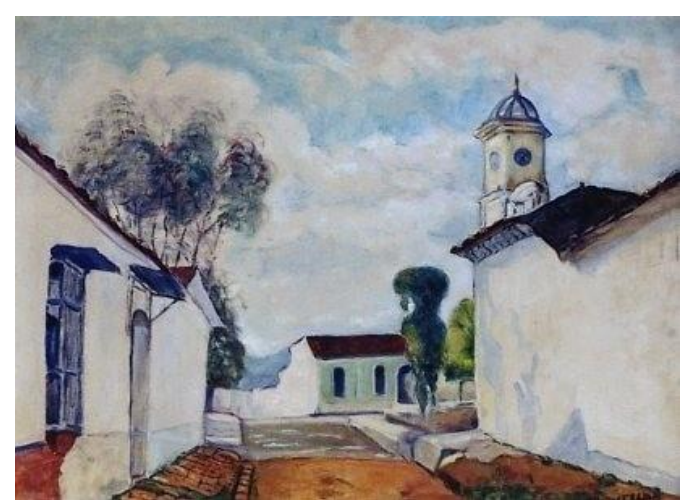

Figura 11 


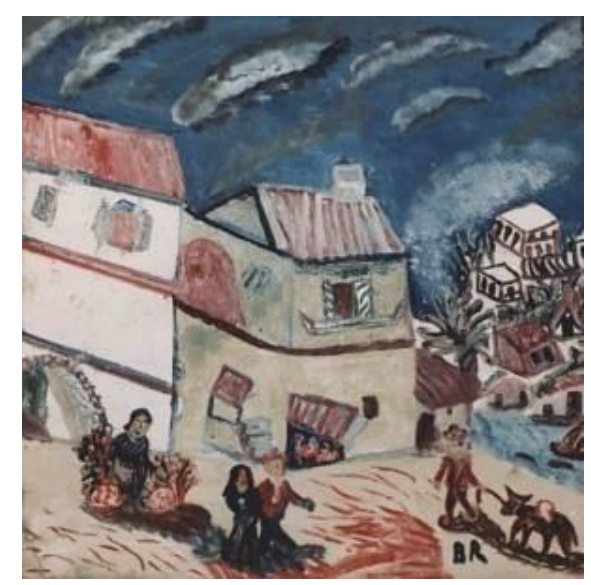

Figura 12

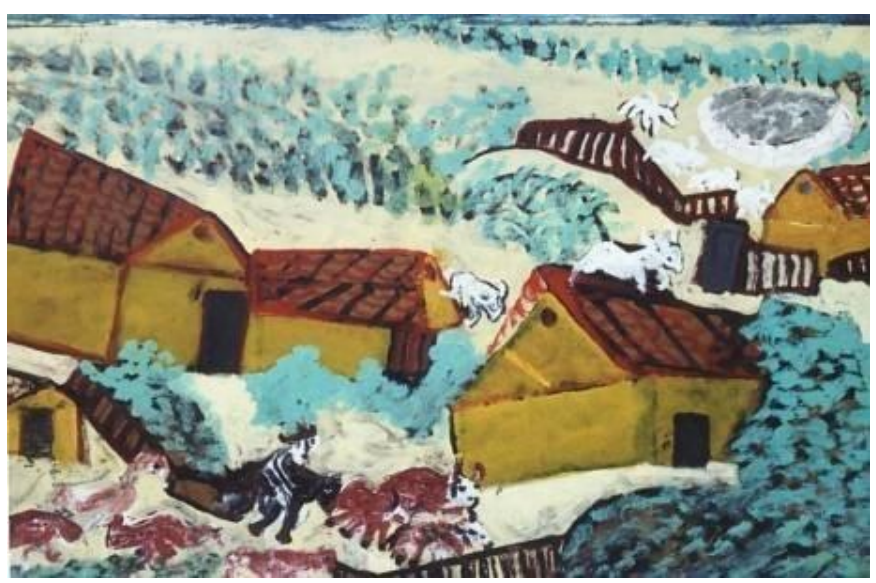

Figura 13

Bárbaro Rivas ( Venezuelano - 1893 -1967). Pintor autodidata é considerado pela crítica como o mais notável dos ingênuos venezuelanos. As tipologias de suas personagens e as ambientes de sua estranha obra estão, sem dúvidas, tomados de Petare, cidade onde sempre viveu (figuras 12 e 13).

Alfredo Helsby Hazell ( Valparaíso -1862 -1933). Em 1906, lhe foi concedida bolsa de estudos para a Europa, tendo se radicado em Paris. Regressou ao Chile em 1908. Herdeiro de uma sensibilidade inglesa para a cor, admirava os paisagistas Whistler e Turner e, dessa maneira, interpretou as paisagens cordilheiras, campos, marinhas, as cenas de Valparaíso e do sul de Chile ( figura 14).

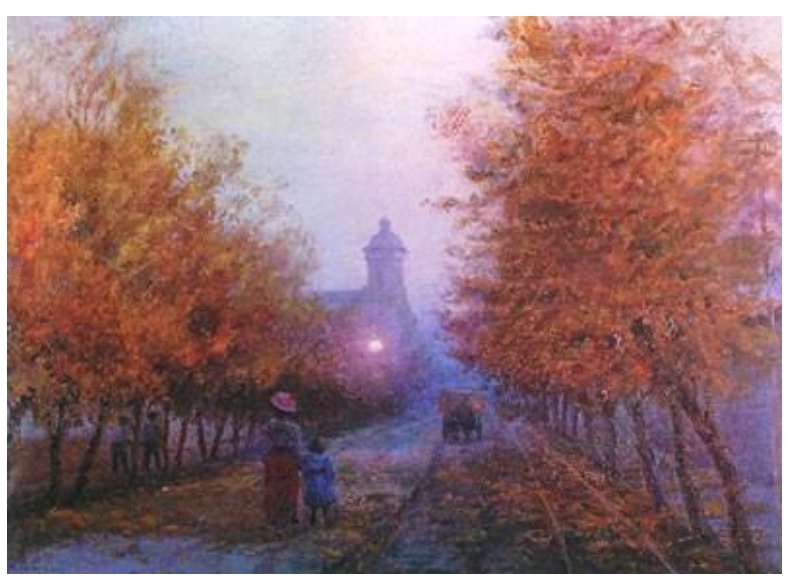

Figura 14



Figura 15

Camilo Mori Serrano (Chile 1896 - 1973) .Em 1920, recebeu bolsa do governo chileno para estudar na Europa por três anos. Foi para a Academia de Roma e, finalmente, instalou-se em Paris no apogeu do movimento modernista. Retornando ao Chile, uniu-se aos pintores do Grupo Montparnasse, o qual foi decisivo na difusão das novas correntes pictóricas francesas no Chile.( figura 15).

Luis Herrera Guevara (Santiago 1891 -1945). Após uma viagem a Europa, na 
qual percorreu os principais centros de artes, inscreveu-se nos ateliês da Sociedade de Belas Artes de Santiago. Fazia uso de cores que ele mesmo chamava de artificiais e desdenhava das tonalidades naturais das paisagens campestres, preferindo as cores brilhantes da cidade, na qual retratou com um completo desapego as perspectivas e proporções. Recriou a vida da cidade de Santiago. Criou um universo pessoal composto por figuras humanas deformes e em atitudes irreais, ruas, edifícios, praças e igrejas distorcidas.( figuras 16 e 17).

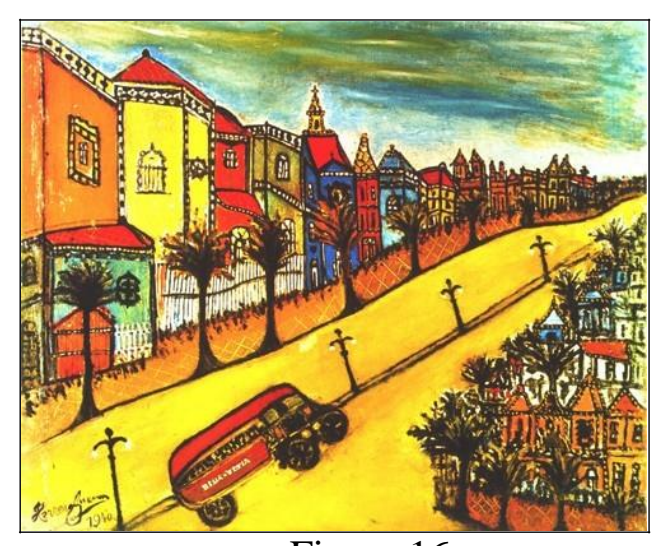

Figura 16

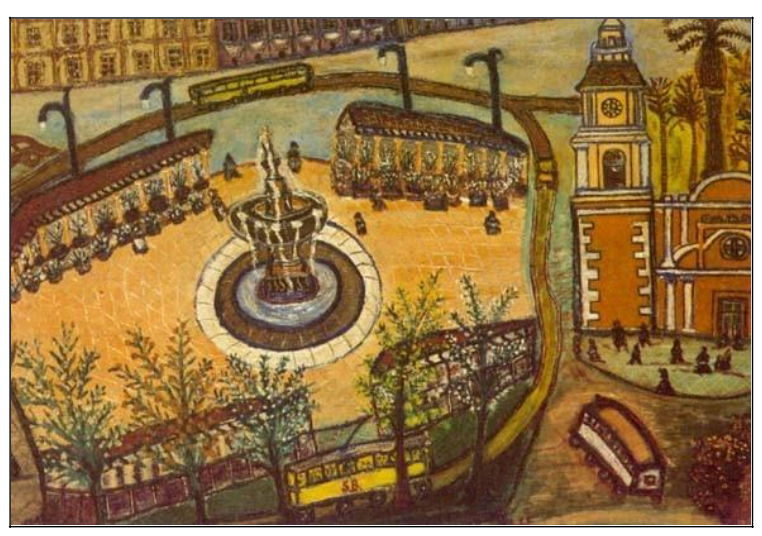

Figura 17

Pedro Figari ( Montevidéu-1861 -1938), em 1925 mudou-se para Paris. De lá, projetou e organizou exposições na Europa e América. Regressou ao Uruguai em 1933. Pedro Figari foi um pintor de manchas e não de linhas. Pintou o passado através de suas lembranças. Povoou seus quadros com gaúchos, negros e crioulos com metáforas de um ser presumidamente uruguaio.( figuras 18 e 19).

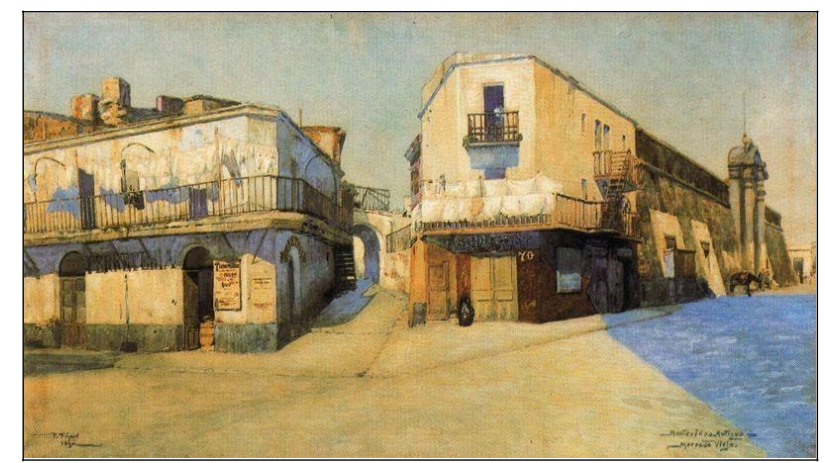

Figura 18

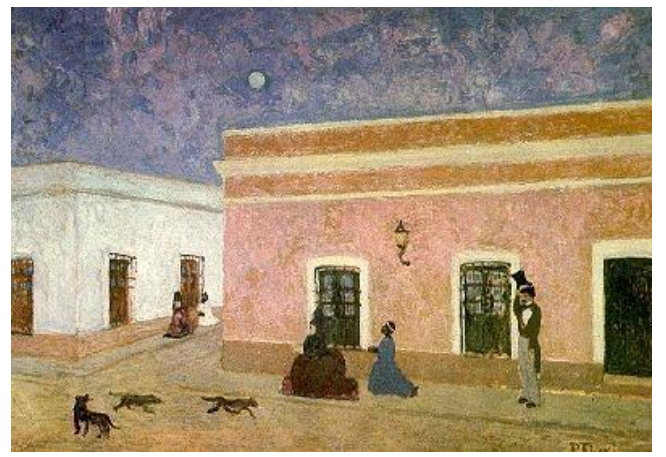

Figura 19 


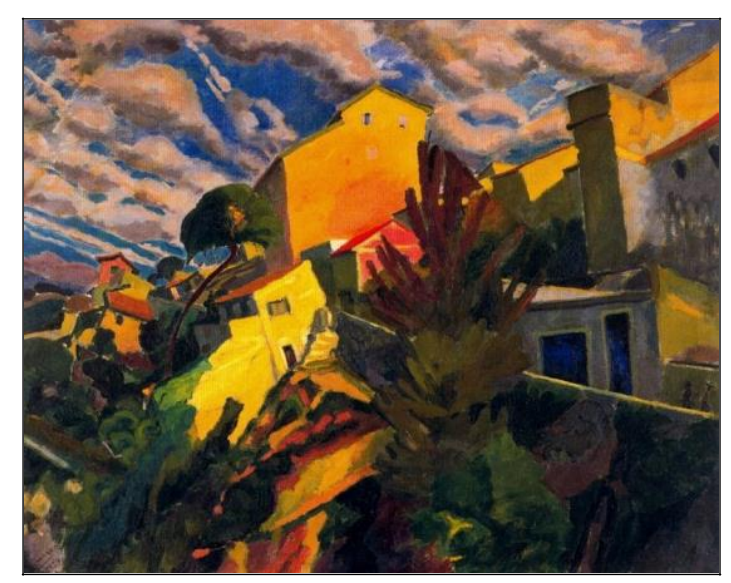

Figura 20

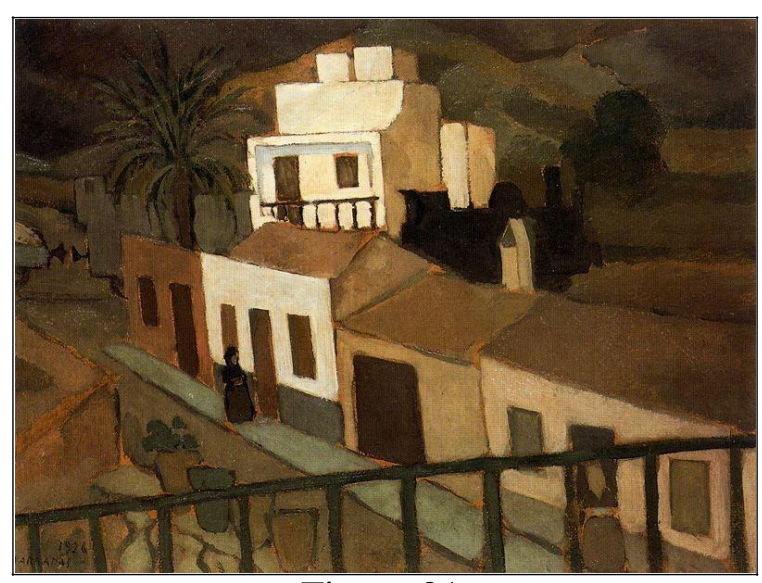

Figura 21

José Cuneo (Montevidéu -1887 -1977 -Alemanha). Em 1917 estudou em Paris e se interessou pela pintura de Cézanne e Gauguin. De volta ao Uruguai, realizou uma série de retratos e paisagens da cidade de Melo. Em 1927, de volta a Europa conheceu a obra de Chaim Soutine atraindo-lhe as deformações expressionistas e o uso da diagonal, o que marcará sua obra futura. A partir de 1930 começou uma série de ranchos, luas e aquarelas do campo uruguaio. (Figura 20)

Rafael Barradas ( Montevidéu 1890 -1929). Durante sua estadia em Barcelona se uniu a Joaquín Torres García Até 1920 viveu em Madrid Mudou-se para Hospitalet de Llobregat, Barcelona, onde realizou uma série de paisagens da localidade. ( figura 21).

Joaquín Torres García (Montevidéu 1874-1949). Radicou-se na Europa por quarenta e três anos. Em 1928, conheceu Theo Van Doesburg, artista que lhe apresentou o neoplasticismo e também Mondrian, que será decisivo na pintura de Torres Garcia. Inspirando-se no seu ambiente, Torres-García desenvolveu obras esquemáticas e simbólicas que evocavam o desenho e o ritmo da cidade, onde registra as formas e as cores das casas estreitas e das ruas vertiginosas de Montevidéu.( figuras 22 e 23).

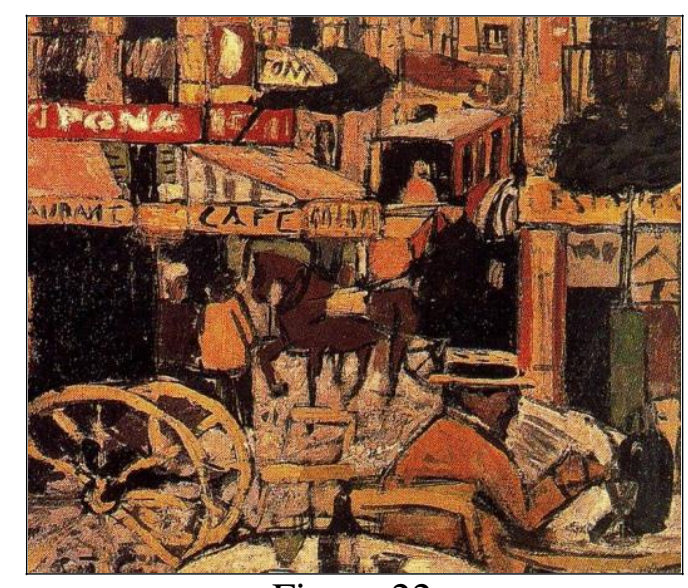

Figura 22

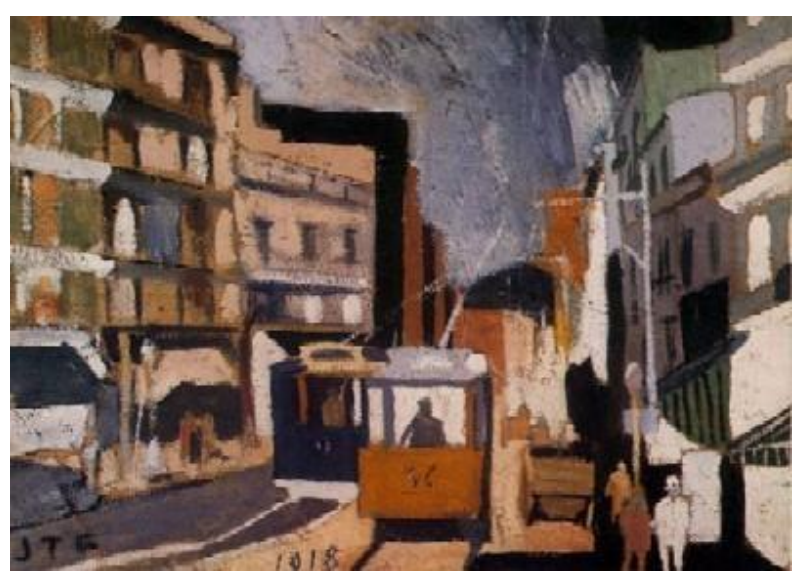

Figura 23 


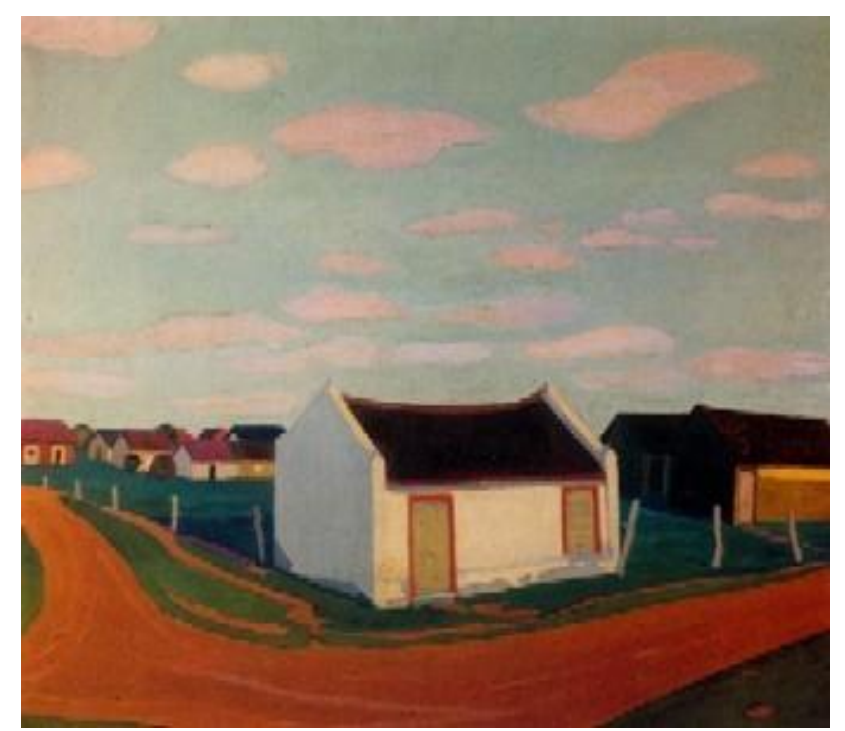

Figura 24

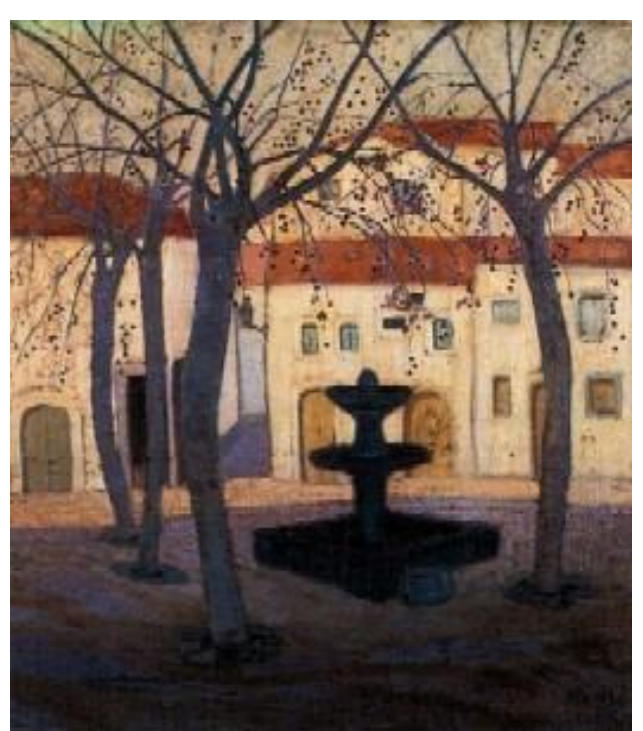

Figura 25

Humberto Causa (Montevidéu -1890 - 1925). Através de uma bolsa de estudos conheceu a Alemanha, Itália, França e Espanha. Em 1918, ao regressar ao Uruguai, radicou-se na região de Maldonado, para se dedicar ao ensino e a pintura da paisagem daquela localidade ( figuras24 e 25).

Em Santa Catarina, Eduardo Dias (Florianópolis, 1872 -1945) foi um dos pintores que mais retratou Florianópolis em seu isolamento. As paisagens do Morro do Antão, as da ponte Hercílio Luz e as da minúscula cidade adquirem um sentido quase metafísico ao lado de uma atmosfera poética. Vemos um olhar mais livre e ingênuo da paisagem e do belo casario da antiga Desterro. A pintura "Colégio de Jesuítas" mostra em suas minúcias, as particularidades de um registro da vida cotidiana da cidade. ( figuras 26 e 27) )

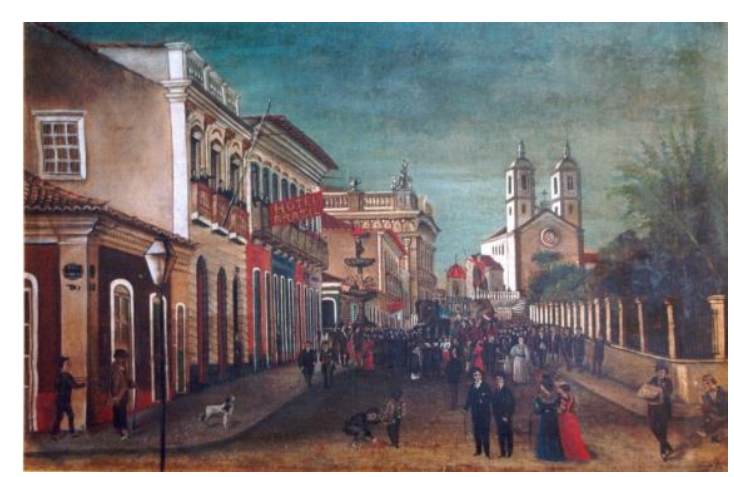

Figura 26

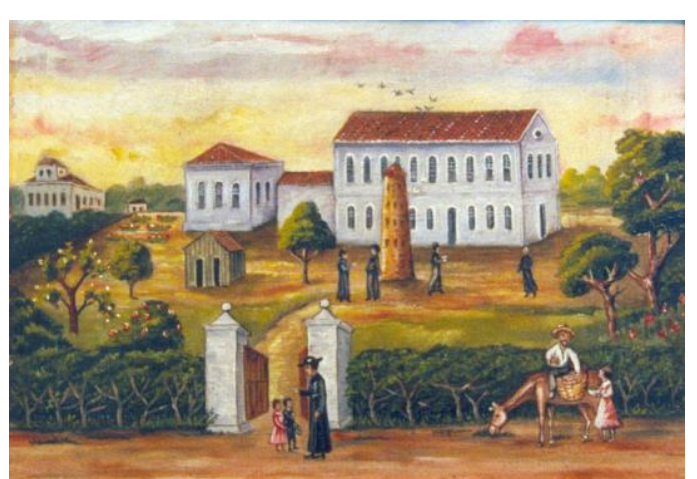

Figura 27

Martinho de Haro (1907-1985) ganhou prêmio de viagem à Europa e estudou em Paris. Não deu saltos para novas tendências, foi fiel as intenções construtivas da diretriz 
moderna, rigoroso controlador dos meios expressivos, de sua fidelidade aos temas e "de quebra, ajudou a criar a memória afetiva da cidade" ( ANDRADE FILHO, 2007, p. 37). ( figuras 28 e 29).



Figura 28

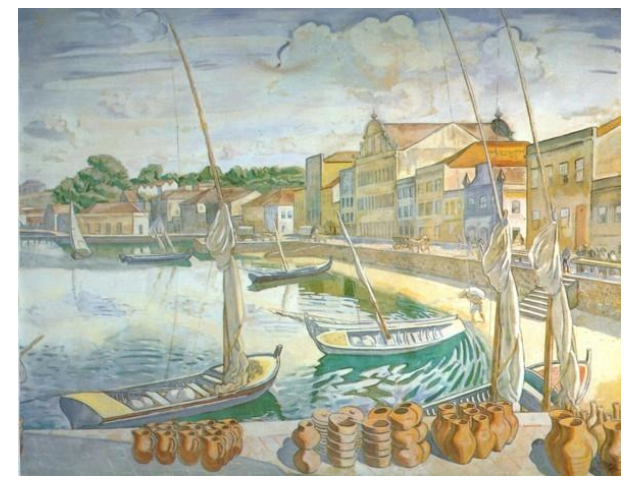

Figura 29

Concluindo- Nesta seqüência de imagens de cidades feitas por artistas que mantiveram, em sua maioria, contato com experiências européias, se percebe uma matriz discursiva que não é européia tão somente, mas sim, particular de cada artista, impregnada de suas vivências e pensamentos. E a rua aparece sempre. Para Fabris (2000), a rua é o lugar tópico da modernidade: niveladora; transformadora das línguas; vitrine do conforto humano, posto que proporciona ao animal civilizado coisas como luz, luxo, bem-estar, comodidade; local de espreita da vida; criadora de tipos; inventora de novas formas de comunicação. A cidade da memória coletiva descrita por Maurice Halbwachs ( 1990) está sempre em transformação e o seu esquecimento significa que os grupos que dela guardavam lembranças, desapareceram. Para Boyer ( 1994) as relações fundamentais entre arquitetura, forma urbana e história devem ser questionadas, pois a cidade é a expressão coletiva da arquitetura e carrega na sua trama e no desenredo de seu tecido os traços de memória de formas arquitetônicas mais antigas, planos diretores e monumentos públicos. As demandas e pressões da realidade social constantemente afetam a ordem material da cidade, contudo ela permanece sendo o teatro de nossa memória. Suas formas coletivas e reinos privados nos contam das mudanças que estão acontecendo; nos lembram também de tradições que diferenciaram esta cidade de outras. São nesses artefatos físicos e traços que nossas memórias da cidade jazem enterradas, pois o passado é carregado até o presente através desses lugares. Endereçados ao olho da visão e à alma da memória, as ruas de uma cidade, monumentos e formas arquitetônicas constantemente contêm grandes discursos sobre a história. A imagem da cidade é um conceito abstrato, uma forma construída imaginariamente. 


\begin{abstract}
Modelo, espacial, social e cultural, a cidade apresenta-se, não raras vezes, como o território privilegiado da utopia. Em muitas "arquiteturas pintadas", como no caso do renascimento, configura-se o desejo utópico de construir modelos ideais, projeções de uma visão de mundo, um pensamento filosófico, que só em poucas ocasiões terão a oportunidade de transformar-se em realidade ( FABRIS, 2000, p.9).
\end{abstract}

Mas a arquitetura na cidade não é somente um espetáculo moldado pela ordem representacional dos planejadores e arquitetos, ela envolve também o público. Como espectadores, nós viajamos através da cidade observando seus espaços arquitetônicos construídos, mudando cenários contemporâneos e reflexões do passado até que eles se condensem em uma visão personalizada. Nossa memória da cidade é especialmente cênica e teatral: nós viajamos de volta no tempo através de imagens que lembram partes e pedaços de uma cidade anterior, nós projetamos essas representações anteriores em cenários recompostos unificados e nos apaixonamos por estes cenários infinitos.

\title{
Referências bibliográficas
}

ANDRADE FILHO, João Evangelista. Um moderno na província. IN: MATTOS, Tarcísio; Corrêa Neto, Ilmar; Andrade Filho, João Evangelista (orgs). Martinho de Haro. Florianópolis: Tempo Editorial, 2007. p. 31 - 51.

ARGAN, Carlo Giulio. A história da arte como história da cidade. São Paulo: Martins Fontes, 1998.

BARATA, MÁRIO. In: Arte moderna no Salão Nacional. Rio de Janeiro: MEC/Funarte, 1983.

BOYER, M. Cristine. The City of Collective Memory: Its Historical Imagery and Architectural Entertainments. Cambridge Mass.: MIT Press, 1994.

BRADBURY,M. E MCFARLANE, J.Modernismo-Guia geral. São Paulo: Companhia das Letras, 1989.

CERTEAU, M. A invenção do cotidiano. Petrópolis: Ed. Vozes, 2003.

CHEREM, Rosangela Miranda. Notações para uma história da pintura na América Latina. Jornada de pesquisa da UDESC, CEART, 2008.Site: http://www.ceart.udesc.br/revista_dapesquisa

CHIARELLI, Tadeu. Entre Almeida Júnior e Picasso. In: FABRIS, Annateresa ( org). Modernidade e modernismo no Brasil. Campinas: Mercado de Letras, 1994, p.57-65.

FABRIS, Annateresa. Fragmentos urbanos: representações culturais. São Paulo: Studio Nobel, 2000.

FABRIS, Annateresa. Modernidade e Vanguarda: o caso brasileiro. In: (org.).

Modernidade e Modernismo no Brasil. Campinas: Mercado de Letras, 1994. p.20.

FRANCASTEL, P. A realidade figurativa. São Paulo: Perspectiva, 1982

FRANCASTEL, Pierre. Pintura e sociedade.São Paulo: Martins Fontes, 1990.

GOMBRICH, E.H. Arte e ilusão. Um estudo da psicologia da representação pictórica.

São Paulo: Martins Fontes, 1986.

GONÇALVES, Denise et al. CIDADE HISTÓRICA NA CONTEMPORANEIDADE PRESSUPOSTOS TEÓRICOS PARA UMA ANÁLISE DAS FORMAS URBANAS. 
HALBWACHS, Maurice - A memória coletiva. São Paulo: Vértice/Editora dos Tribunais, 1990.

HYDE,G.M. A poesia da cidade. In BRADBURY,M. E MCFARLANE,J. Modernismo-Guia geral. São Paulo: Companhia das Letras, 1989.

LEHMKUHL, Luciene. Os modernistas da ilha: obras e exposições do grupo de artistas plásticos de Florianópolis. IN: FLORES, M.B. LEHMKUHL, L. COLLAÇO, V.R.M. (orgs).A casa do Baile: estética e modernidade em Santa Catarina. Florianópolis: Fundação José Boiteux, 2006.

LEPETIT, Bernard. Por uma história urbana - Bernard Lepetit. São Paulo: EDUSP, 2001.

LUCHIARI, M.T. A (re)significação da paisagem no período contemporâneo. In: ROZENDHAL, Z. Paisagem, imaginário e espaço. Rio de Janeiro: EDUERJ, 2001. PEIXOTO, Fernanda Arêas. As cidades nas narrativas sobre o Brasil.In: FRÚGOLI JR; ANDRADE, L.T; PEIXOTO, F.A.(orgs). As cidades e seus agentes: práticas e representações.Belo Horizonte: PUC Minas/Edusp, 2006.

RAMA, Angel.As cidades das letras.São Paulo: Brasiliense, 1985.

REVISTA OHUN - ANO 2 - nº 2 - 2005.Programa de Pós-Graduação em Artes Visuais da Escola de Belas Artes da Universidade Federal da Bahia PPG-AV-EBA-UFBA. Disponível em < http://www.revistaohun.ufba.br/html/cidade_historica.html $>$. Acesso em 19 de jun.2008.

SANTOS, M. apud NEVES, E. Paisagem-conceito. In: Paisagem e ambiente. Ensaios IV. São Paulo: FAUSP, 1992.

SARLO, Beatriz. Buenos Aires: Cidade Moderna IN: Paisagens imaginárias. São Paulo: Editora da USP, 2005. p.199-217.

SILVA, Maria Beatriz Setúbal de Rezende. Preservação na gestão das cidades. In: Revista do Patrimônio Histórico e Artístico Nacional, n. 24, 1996.

Referências das imagens - Figuras

1- Figura 1 -Argentina. Xul Solar. (1887, Buenos Aires - 1963). 'Cidade e abismos', 1946. Têmpera e aquarela s/ cartão 35 x $50 \mathrm{~cm}$. Malba - Coleção Costantini

2- Figura 2. Argentina. Xul Solar. (1887, Buenos Aires - 1963). 'Ciuda Lagui', 1939 Aquarela 37.5 x $50 \mathrm{~cm}$.

3 Figura 3. Argentina. Xul Solar. (1887, Buenos Aires - 1963). 'Barrio', 195Têmpera $40 \times 56 \mathrm{~cm}$

Xou Solar. Disponível em < http://www.zaz.com.br/bienal/xul.htm>. Acesso em 22 jul.2007.

4- Figura 4. Argentina. Antonio Berni. Sueño de uma noche de verano a orillas del lago gardas - 1931

5- Figura 5.Argentina .Antonio Berni. 'El tanque blanco', 1956.

6- Figura 6.Argentina .Antonio Berni. 'La calle', 1955.

7- Figura 7.Argentina .Antonio Berni. 'La gallina ciega', 1974

Antônio $\quad$ Berni $\quad$ Rosário. $\quad$ Disponível em <http://www.bienalmercosul.art.br/fundacaobienal/site/controller.jsp?c=viewArtistDetai 1s\&artist.uid=229. $>$ Acesso em 13 jul. 2007.

Disponível em < http://en.wikipedia.org/wiki/Antonio_Berni.>Acesso em 13 jul.2007.

8-Figura 8. Honduras. Jose Antonio Velasquez .Santo Antonio do Oriente, 1949. Óleo sobre tela. $52.07 \times 76.2 \mathrm{~cm}$.

9 Figura 9. Honduras.Jose Antonio Velásquez. Vila de Santo Antonio do Oriente. 
José Antônio Velazques. Disponível em http://www.honduras.com/museum/jvelas1.htm>. Acesso em 23 jul. 2007.

10. Figura 10. Venezuela. Rafael Monasterio.Calle de Quíbor', 1957 Óleo s/ masonite $60 \times 80 \mathrm{~cm}$.

11-Figura 11.Venezuela. Rafael Monasterio..Barrio de Duaca', 1956 Óleo s/ tela 64 x $84 \mathrm{~cm}$.

Rafael Monasterio. Disponível em http://www.morellajimenez.com.do/pinturamonasterios.htm> Acesso em 10 ago. 2007. 12-Figura 12.Venezuela. Bárbaro Rivas.Vista de Pueblo (Escenas Pueblerinas)',1960 Óleo s/ masonite $46 \times 46 \mathrm{~cm}$.

13- Figura 13. Venezuela. Bárbaro Rivas. 'Barrio Caruto' (segunda versión),1925

Esmalte s/ masonite $52 \times 68 \mathrm{~cm}$

Bárbaro Rivas- Disponível em < http://www.galeriamuci.com/artistas/rivas.htm> Acesso em 24 jul. 2007.

Disponível em < http://www.bcv.org.ve/BLANKSITE/c3/colecarte/rivas_index.htm> Acesso em 24 jul. 2007.

14. Figura 14. Chile. - Alfredo Helsby Hazell, (n.Valparaíso - 1862 - f.Santiago 1933).Igreja Divina Providência, s/ data. Óleo s/tela, 55 x $76 \mathrm{~cm}$. Coleção particular. Alfredo Helsby. Disponível em < . http://www.mapocho.org/wpcontent/uploads/alfredo_helsby_providencia.jpg> Acesso em 19 jul. 2007.

15. Figura 15. Chile. Camilo Mori Serrano.Domingo em Valparaiso, s/ data.

Camilo Mori Serrano. Disponível em < www.artistasplasticoschilenos.cl>. Acesso em 18 mai.2007.

16- Figura 16. Chile. - Luis Herrera Guevara.. Cerro Bellavista, 1940. Óleo s/ tela.

Pinacoteca Banco Central de Chile, Santiago.

17. Figura 17. Chile - Luis Herrera Guevara. Igreja de São Francisco e Praça das Flores, s/ data. Óleo s/ tela. Coleção particular.

Luis Herrera Guevara. Disponível em < www.artistasplasticoschilenos.cl > e disponível em < www.mac.uchile.cl/virtual/h2/index.html $>$. Acesso em 24 mai.2007.

18- Figura 18. Uruguai. Pedro Figari, L'Ancien Montevideo: le vieux marché, 1890.Aquarela. 50 x $80 \mathrm{~cm}$. Museo Histórico Nacional, Casa de Fructuoso Rivera. Montevideo

19. Figura 19. Uruguai.- Pedro Figari, (Montevidéu - 1861 / Montevidéu - 1938) Toque de oración, 1925, óleo s/ cartão, 69 x 99 cm. Coleção Museu Nacional de Artes Visuais de Belas Artes.

Pedro Figari. Disponível em < http://www.mnav.gub.uy/figari.htm> Aceso em 10 abr.2007.

20. Figura 20. Uruguai - José Cuneo. Caserío de Cagnes, 1929. Óleo s/ tela. 74 x 92

$\mathrm{cm}$. Coleção Museu de Arte Latino-americano de Buenos Aires - MALBA. Argentina Jose Cuneo. Disponível em < http://www.mnav.gub.uy/cuneo.htm> e Disponível em http://www.rau.edu.uy/uruguay/cultura/cuneo.htm Acesso em 12 mai.2007.

21.Figura 21. Uruguai - Rafael Barradas. Paisaje de Hospitalet. 1926. óleo s/ cartão. 48 x $64 \mathrm{~cm}$.. Coleção Guillermo de Osma. Madrid. Espana.

Rafael Barradas. Disponível em < http://www.mnav.gub.uy/barradas.htm >. Acesso em 11 fev.2007. Disponível em < http://www.museopatioherreriano.org/MuseoPatioHerreriano/coleccion/catalogo_raz onado $>$. Acesso em 11 fev.20076.

22. Figura 22. Uruguai- Joaquím Torres Garcia.Escena Callejera, 1918 
Torres Garcia. Disponível em < http://www.mnav.gub.uy/torres.htm> e Disponível em $<w w w . t o r r e s g a r c i a . o r g . u y . j p g>$. Acesso em 02 fev.2007.

23. Figura 23. URUGUAI - Joaquím Torres Garcia, (Montevidéu - 1874/ Montevidéu 1949). Paisaje de ciudad, 1928. Óleo s/ cartão. 36 x $56 \mathrm{~cm}$.

24. Figura 24. Uruguai - Humberto Causa. Palma de Mallorca, 1915 .óleo s/ tela. 119 x 135 cm.Coleção Museu Nacional de Artes Visuais, Montevidéu, Uruguay.

25. Figura 25. Uruguai - Humberto CausaPlaza de Pollenza, 1915.Coleção Museu Nacional de Artes Visuais, Montevidéu, Uruguay.

Humberto Causa. Disponível em < http://www.mnav.gub.uy/causa.htm>Acesso em 20 mai.2007.

26. Figura 26. - Brasil. Eduardo Dias - "Colégio de Jesuítas", s/d. Óleo sobre tela - 23,5 x $33 \mathrm{~cm}$. Acervo do MASC, tombo no 418 .

27. Figura 27. Brasil. Eduardo Dias. "Netos do Diabo", s/d. Óleo sobre tela Circa 1,50 x $80 \mathrm{~cm}$. Coleção Edhy Francisco Mattos.

28. Figura 28.Brasil. Martinho de Haro. "Panorama de Florianópolis". Óleo sobre eucatex. 63 x $113 \mathrm{~cm} .1975$. Acervo do MASC.

29. Figura 29. Martinho de Haro -“Porto". Óleo sobre eucatex. 211 x $271 \mathrm{~cm}$. Acervo

Teatro Álvaro de Carvalho (TAC). 